\title{
Involvement and Perceived Argument Quality in Central and Peripheral Persuasion and Effectiveness of Advertisement
}

\begin{abstract}
Yuchen Huang
Nanjing Foreign Language School, Nanjing, 210008, China

13851834436@163.com

ABSTRACT

The past decades have witnessed a booming economy and expanding market all over the world. Under such currents, advertisements have achieved unprecedented success in promoting products and helping companies earn profits. Elaborately designed advertisements appeal to people's emotions and raise their desires to buy the product. Various advertisements in the market can be divided into three categories: central persuasion advertisement, peripheral persuasion advertisement, and the combination of these two types. This study focuses on comparing the effect of central persuasion with peripheral persuasion in advertising. It also tests the impacts of consumers' perceived argument quality and involvement on evaluating the advertisement's effectiveness. The main methods used in data analysis are reliability and validity test, correlation test, and regulatory test. Finally, the study finds that when people perceive the argument in the advertisement to be stronger, their desire to purchase the product will increase. We also find that central persuasion is more effective in persuading consumers when they are under high than low involvement. In contrast, peripheral persuasion changes consumers' attitudes to the same extent under both levels of involvement. This study provides empirical evidence to the design of advertisements and give companies new insights into creating advertisements that appeal to more costumers under different circumstances.
\end{abstract}

Keywords: Central and peripheral persuasion, advertising, argument quality, involvement, effectiveness of advertisement.

\section{INTRODUCTION AND LITERATURE OVERVIEW}

Advertisements can influence consumers' desire to buy the product by changing their attitudes and behavioral patterns (Vakratsas \& Ambler, 1999).[1] Therefore, companies can change the way of persuasion in their advertisements to effectively increase their sales. The elaboration likelihood model (ELM) of persuasion was first mentioned by Petty and Cacioppo (Petty \& Cacioppo, 1986).[2] The ELM model contains two ways of persuasion: central route persuasion, and peripheral route persuasion. Central route persuasion in advertisement concentrates on putting forward factual basis of products such as material and core technology to inform consumers of the characteristics, performance, and usage of the products. Peripheral route persuasion in advertisement focuses on emotional appeals in advertising based on the emotional needs of the audience, and facilitates people to form form a positive attitude toward the commodity.

\section{EXPERIMENT METHOD}

\subsection{Procedure}

One hundred and fifty students aged between 16 and 20 participated in this experiment. The design of the experiment was a 2 (type of persuasion: central or peripheral) x 2 (involvement: high or low) factorial. Participants joined an online group meeting and watched a video advertising the Adidas Boost Shoes. Each participant would watch both central and peripheral persuasion advertisements. Then they were asked to complete a questionnaire after watching each video.

The questionnaire contained information about their evaluations on both advertisement content and the effectiveness of advertisement. Since different people 
perceived the same argument to be of varying quality, even when they were watching the same argument, some people might find the message of high quality, while others might not. To study the relationship between participants' own perception of argument quality and their evaluated effectiveness of argument, participants were first asked to answer three questions about how strong they perceived the argument quality in the advertisement to be. We took this step in both central and peripheral experiments. Similarly, we asked participants to evaluated their level of involvement on their own since individuals might feel different level of relevance to the same object. Finally, they were asked to give a score for their comprehensive judgment of the product and evaluate their desire to buy it. This final score determined the effectiveness of the advertisement.

The questionnaire was like the Likert Scale, including five choices such as " dislike, quite dislike, no feeling, quite like, like." Scores from 1-5 were assigned to each choice from the lowest level to the highest level. Each part (central/peripheral argument, level of involvement, final score) contained three questions, and the score used in the data analysis was the average score to the three questions in each part.

\subsection{Independent variables}

\subsubsection{Type of persuasion}

In the experiment, all the participants watched two videos shown in figure $1 \& 2$ advertising the same product: the Adidas Boost Shoes. The video lasted about 1 minute. The central route persuasion advertisement included detailed introduction about the material and advantage of the shoes, while the peripheral route persuasion advertisement comprised a exciting story to promote the product.

\subsubsection{Level of involvement}

In the pilot study conducted by Petty and Cacioppo in 1979, participants were asked to decide whether the school should increase tuition (Petty \& Cacioppo, 1984). [3] The experimenters adjusted the level of involvement by telling the high involvement group that this change would be made in their university and telling the low involvement group that this change would be implemented in a distant university. However, we thought that the level of involvement was participants' own perception and could vary from individuals. So we decided to let participants give their own evaluations about their level of involvement. The score range was 15 , and we considered a score $\geqslant 2.5$ to be high involvement and a score $<2.5$ to be low involvement.

\subsection{Dependent variable}

Evaluated effectiveness of the advertisement To evaluate the effectiveness of specific advertisement, we asked all the participants to complete a questionnaire concerning their evaluation of the advertisement's content and effectiveness. Then the average score was computed for further analysis.

\subsection{Hypothesis}

We hypothesized that 1) Central persuasion is more effective than central persuasion in advertising the Adidas Boost Shoes. 2) Under normal circumstances, both central and peripheral persuasion can positively increase consumers' desire to buy the product. 3) Central persuasion will generate a more significant difference in the effectiveness under high than under low level of involvement.

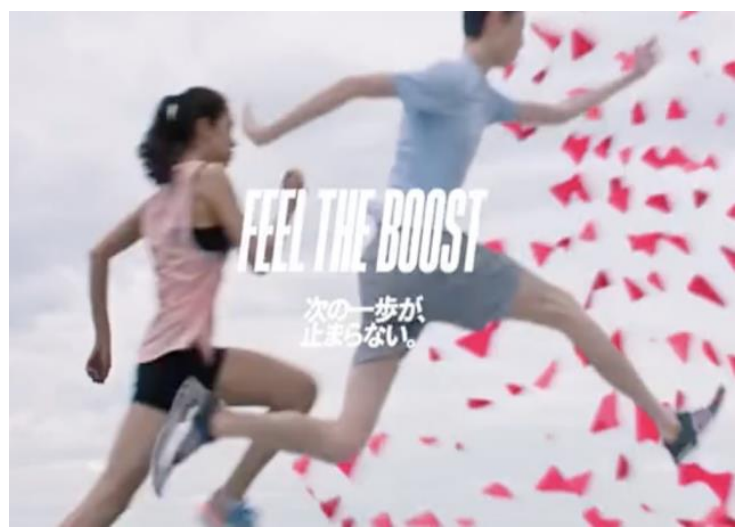

Figure 1 Peripheral persuasion advertisement

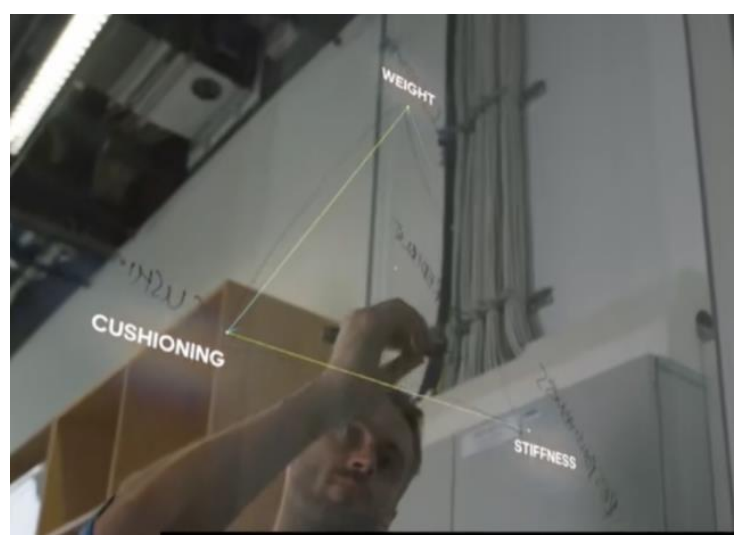

Figure 2 Central persuasion advertisement

\section{DATA ANALYSIS}

Since we gathered data through online questionnaires, we needed to test the validity and reliability of the data collected. We did the reliability analysis and validity analysis to test whether the design of our questionnaire was reasonable and whether the data was reliable. 


\subsection{Reliability Analysis}

Table 1. Reliability Analysis

Cronbach Reliability Analysis

\begin{tabular}{|c|c|c|c|c|}
\hline Variable & Statement & $\begin{array}{l}\text { Corrected } \\
\text { Item-Total } \\
\text { Correlation } \\
\text { (CITC) }\end{array}$ & $\begin{array}{l}\text { Cronbach's } \alpha \\
\text { if Item } \\
\text { Deleted }\end{array}$ & Cronbach's $\alpha$ \\
\hline \multirow[b]{2}{*}{$\begin{array}{l}\text { Central } \\
\text { advertisement }\end{array}$} & $\begin{array}{l}\text { 1. The advertisement can clearly introduce the } \\
\text { characteristics, performance, and use method of } \\
\text { the product. }\end{array}$ & 0.679 & 0.609 & \\
\hline & $\begin{array}{l}\text { 2.The advertisement can clearly introduce } \\
\text { function, quality, technology used of the product. } \\
\text { 3. The advertisement is convincing in its } \\
\text { introduction of the product. }\end{array}$ & 0.574 & 0.724 & 0.771 \\
\hline $\begin{array}{c}\text { Peripheral } \\
\text { advertisement }\end{array}$ & $\begin{array}{l}\text { 1.The advertisement has a full immersive story. } \\
\text { 2.The advertisement has a touching and exciting } \\
\text { theme. } \\
\text { 3. The celebrity in this advertisement is familiar to } \\
\text { me. }\end{array}$ & 0.758 & $\begin{array}{l}0.707 \\
0.817\end{array}$ & 0.834 \\
\hline Involvement & $\begin{array}{l}\text { 1.The advertising information can help me find } \\
\text { related product information. } \\
\text { 2.The advertising information can effectively help } \\
\text { me make decision. } \\
\text { 3.I feel personally related to the advertisement. }\end{array}$ & 0.644 & 0.752 & 0.808 \\
\hline \multirow{2}{*}{$\begin{array}{l}\text { Effectiveness } \\
\text { of } \\
\text { advertisement }\end{array}$} & $\begin{array}{l}\text { 1. The number of arguments I can remember after } \\
\text { watching the advertisement }\end{array}$ & 0.688 & 0.568 & \multirow{2}{*}{0.763} \\
\hline & $\begin{array}{l}\text { 3. The desire to buy the product after watching } \\
\text { the advertisement. }\end{array}$ & 0.515 & 0.766 & \\
\hline
\end{tabular}

As can be seen from table 1, the reliability coefficients were all greater than 0.7 , indicating that the reliability of the research data was good. For the " Cronbach's $\alpha$ coefficient if item deleted", the reliability coefficient did not increase significantly after any item was deleted, so it indicated that item should not be deleted.
In summary, the data collected in the questionnaire was of high quality and can be used for further analysis.

\subsection{Validity analysis}

In order to test the validity of the design of our questionnaire, we did the validity analysis. 
Table 2. Validity Analysis

Validity Analysis

\begin{tabular}{|c|c|c|c|c|c|}
\hline \multirow{2}{*}{ Statement } & \multicolumn{4}{|c|}{ Factor loading } & \multirow{2}{*}{ Communality } \\
\hline & 1 & 2 & 3 & 4 & \\
\hline $\begin{array}{l}\text { The advertisement can clearly introduce the } \\
\text { characteristics, performance, and use method of the } \\
\text { product. }\end{array}$ & -0.019 & 0.057 & 0.895 & 0.021 & 0.805 \\
\hline $\begin{array}{l}\text { The advertisement can clearly introduce function, quality, } \\
\text { technology used of the product. }\end{array}$ & 0.185 & 0.052 & 0.815 & 0.047 & 0.704 \\
\hline $\begin{array}{l}\text { The advertisement is convincing in its introduction of the } \\
\text { product. }\end{array}$ & 0.084 & 0.139 & 0.705 & 0.356 & 0.65 \\
\hline The advertisement has a full immersive story. & 0.877 & 0.124 & 0.041 & 0.182 & 0.82 \\
\hline The advertisement has a touching and exciting theme. & 0.725 & 0.176 & 0.148 & 0.303 & 0.669 \\
\hline The celebrity in this advertisement is familiar to me. & 0.847 & 0.135 & 0.084 & 0.17 & 0.771 \\
\hline $\begin{array}{l}\text { The advertising information can help me find related } \\
\text { product information. }\end{array}$ & 0.08 & 0.889 & 0.071 & 0.016 & 0.803 \\
\hline $\begin{array}{l}\text { The advertising information can effectively help me make } \\
\text { decision. }\end{array}$ & 0.223 & 0.804 & 0.048 & 0.039 & 0.701 \\
\hline I feel personally related to the advertisement. & 0.087 & 0.791 & 0.105 & 0.211 & 0.689 \\
\hline $\begin{array}{l}\text { The number of arguments I can remember after } \\
\text { watching the advertisement }\end{array}$ & 0.227 & -0.027 & 0.032 & 0.873 & 0.816 \\
\hline The completeness of the advertisement. & 0.308 & 0.048 & 0.328 & 0.67 & 0.654 \\
\hline $\begin{array}{l}\text { The desire to buy the product after watching the } \\
\text { advertisement. }\end{array}$ & 0.172 & 0.31 & 0.084 & 0.724 & 0.657 \\
\hline Eigen value (Unrotated) & 4.325 & 1.761 & 1.635 & 1.017 & - \\
\hline$\%$ of Variance(Unrotated) & $36.04 \%$ & $14.68 \%$ & $13.63 \%$ & $8.48 \%$ & - \\
\hline Cumulative $\%$ of Variance(Unrotated) & $36.04 \%$ & $50.72 \%$ & $64.35 \%$ & $72.82 \%$ & - \\
\hline Eigen value (Rotated) & 2.293 & 2.253 & 2.128 & 2.065 & - \\
\hline$\%$ of Variance(Rotated) & $19.11 \%$ & $18.77 \%$ & $17.73 \%$ & $17.21 \%$ & - \\
\hline Cumulative $\%$ of Variance(Rotated) & $19.11 \%$ & $37.88 \%$ & $55.61 \%$ & $72.82 \%$ & - \\
\hline $\mathrm{KMO}$ & \multicolumn{4}{|c|}{0.779} & - \\
\hline Bartlett's Test of Sphericity & \multicolumn{4}{|c|}{731.429} & - \\
\hline$d f$ & \multicolumn{4}{|c|}{66} & - \\
\hline$p$ value & \multicolumn{4}{|c|}{0} & - \\
\hline
\end{tabular}

In the above table 2, the corresponding common degree values of all research items were higher than 0.4 , indicating that research item information could be effectively extracted. In addition, KMO value was 0.779 , greater than 0.6 , indicating that the data had validity. The variance explanation rate values of the 4 factors are $19.105 \%, 18.772 \%, 17.731 \%, 17.212 \%$ respectively, and the cumulative variance explanation rate after rotation was $72.820 \%>50 \%$. It meant that the information content of the research item could be extracted effectively.

\section{RESULTS}

\subsection{Effectiveness of central and peripheral persuasion}

Generally, the final evaluation of effectiveness in peripheral persuasion model $(M=3.54)$ was higher than central persuasion model $(M=3.31)$, indicating that peripheral persuasion was slightly more effective in advertising this specific product. This was different from our original assumption that central persuasion was more effective in advertising shoes. Our original analysis considered that since shoes were articles of daily use, consumers would concern more about the quality and material of the product, and they would find central persuasion advertisement more convincing. However, the experiment showed the opposite. This was probably because of the participants we chose were among 16-20 years old, and the video length was only about 1 minute. In the future, more work can be done to test participants at different age and change the form of advertisement to figure out which persuasion model is more effective. 


\subsection{Perceived argument quality and effectiveness of advertisement}

Figure 3 and figure 4 showed the distribution of participants' evaluated scores of the argument quality in central persuasion advertisement, peripheral persuasion advertisement, and the level of involvement. The mean score of perceived argument quality in central persuasion ad was $3.51, \mathrm{SD}=0.88$. The mean score of perceived argument quality in peripheral persuasion ad was 3.11, $\mathrm{SD}=1.13$. The mean score of involvement was 3.22 , $\mathrm{SD}=0.96$.
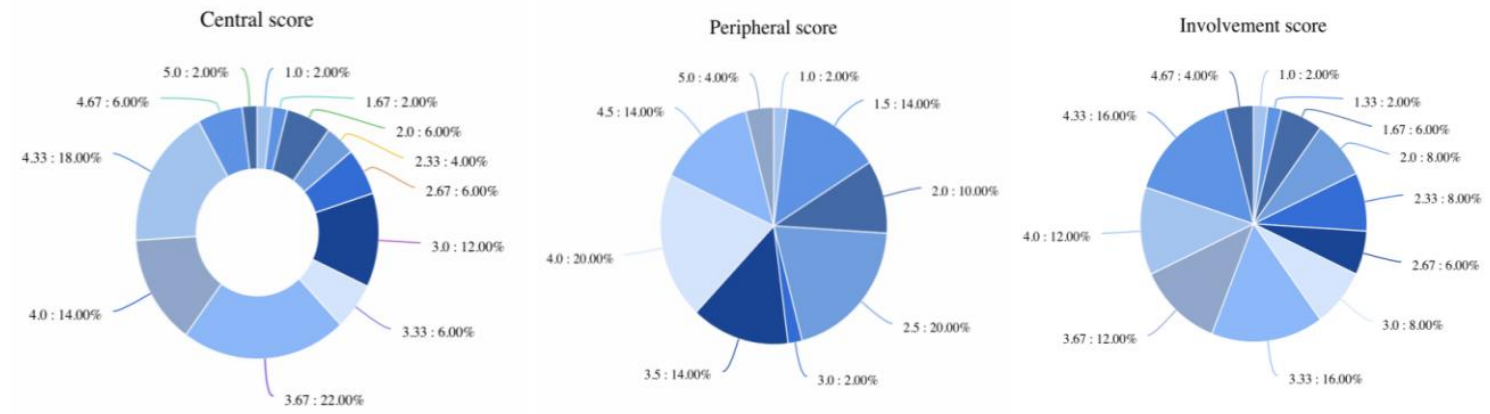

Figure 3 Pie chart of central, peripheral, and involvement scores

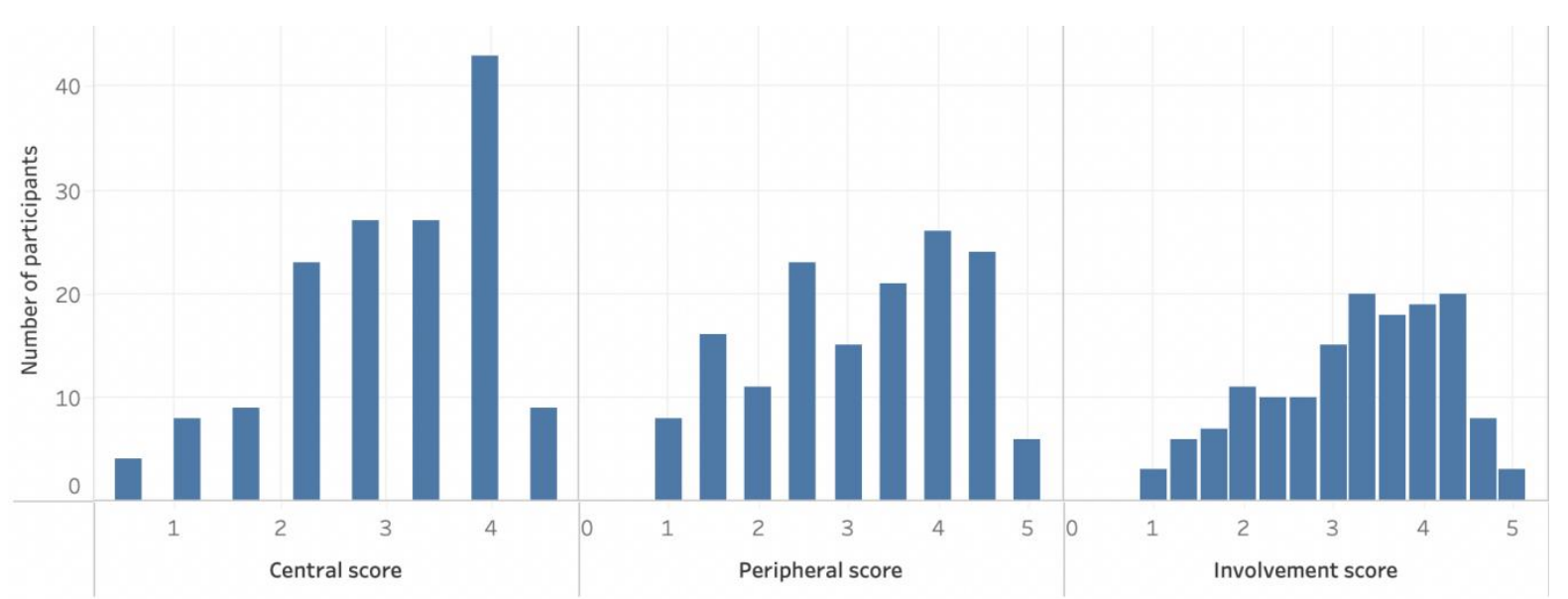

Figure 4 Bar chart of central, peripheral, and involvement scores

\subsection{Correlation test}

Table 3. Correlation test

\begin{tabular}{lcccc}
\hline & & Central & Peripheral & Involvement \\
\hline \multirow{2}{*}{ Effectiveness } & coefficient & $0.387^{\star \star}$ & $0.476^{\star *}$ & $0.361^{*}$ \\
& $p$ value & 0.005 & 0.000 & 0.010 \\
\hline
\end{tabular}

$* p<0.05 * * p<0.01$

As shown in table 3, in the correlation test between central persuasion, peripheral persuasion, involvement and effectiveness of advertisement, the correlation values are $0.387,0.476$ and 0.361 respectively, indicating that there was a positive correlation between and central persuasion, peripheral persuasion, involvement and effectiveness of advertisement. 


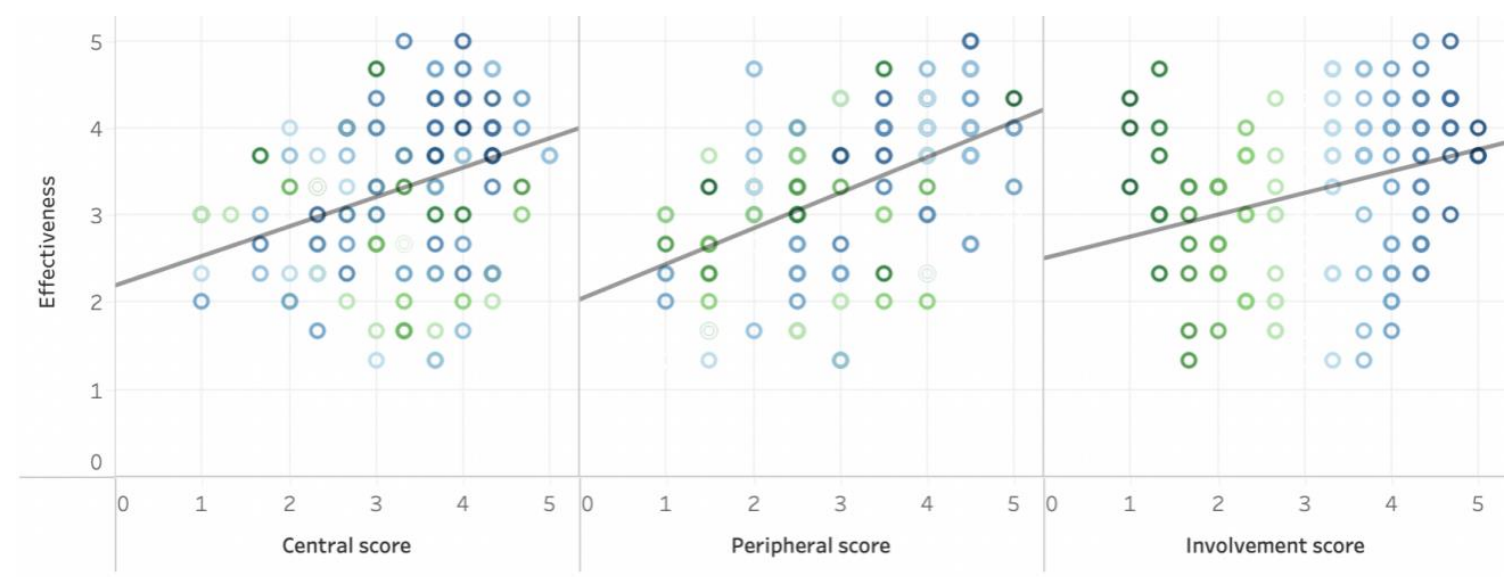

Figure 5 Correlation figure

From the figure 5 above, we can see under that both high and low involvement, as participants perceived central or peripheral arguments to be stronger, they would be more likely to form a positive attitude toward the product and have the desire to buy it. In addition, the effectiveness of advertisement under high involvement $(M=3.32)$ was slightly higher than the score under low involvement $(M=3.29)$. When participants felt that they were highly involved in the experiment and found the product relevant to themselves, they would evaluate the arguments more carefully and pay attention to the content of arguments instead of merely arguments numbers (Petty \& Cacioppo, 1984).[3]

\subsection{The influence of involvement on the effectiveness of advertisement in two ways of persuasion}

In order to study the impact of involvement on the effectiveness of advertisement in both central and peripheral persuasion, we did the regulatory analysis.

Table 4. Regulatory test of central persuasion

\begin{tabular}{|c|c|c|c|}
\hline \multicolumn{4}{|c|}{ Result } \\
\hline & Model 1 & Model 2 & Model 3 \\
\hline \multirow{2}{*}{ Constant } & $3.313^{\star *}$ & $3.313^{\star *}$ & $3.261^{* *}$ \\
\hline & $(47.610)$ & $(48.638)$ & $(48.264)$ \\
\hline \multirow{2}{*}{ Central persuasion } & $0.338^{\star *}$ & $0.297^{\star \star}$ & $0.310^{* \star}$ \\
\hline & $(4.583)$ & $(4.018)$ & $(4.339)$ \\
\hline \multirow{2}{*}{ Involvement } & & $0.192^{* *}$ & $0.181^{* *}$ \\
\hline & & $(2.732)$ & $(2.661)$ \\
\hline Central persuasion * & & & $0.270^{* *}$ \\
\hline Involvement & & & (3.395) \\
\hline Sample size & 150 & 150 & 150 \\
\hline$R^{2}$ & 0.124 & 0.167 & 0.228 \\
\hline Adjusted $R^{2}$ & 0.118 & 0.155 & 0.212 \\
\hline$F$ value & $F(1,148)=21.002, p=0.000$ & $F(2,147)=14.691, p=0.000$ & $F(3,146)=14.336, p=0.000$ \\
\hline$\triangle R^{2}$ & 0.124 & 0.042 & 0.061 \\
\hline$\triangle F$ value & $F(1,148)=21.002, p=0.000$ & $F(1,147)=7.462, p=0.007$ & $F(1,146)=11.524, p=0.001$ \\
\hline
\end{tabular}

Dependent Variable:Effectiveness of advertisement

${ }^{*} p<0.05{ }^{* *} p<0.01$

As shown in the table 4 above, the regulatory effect was divided into three models. Model 1 included independent variable (central persuasion). In model 2, moderating variables (involvement) were added on the basis of Model 1, and in Model 3, interaction terms (product term of independent variable and moderating variable) were added on the basis of Model 2 .
For model 1, the purpose was to study the influence of the independent variable (central persuasion) on the dependent variable (effectiveness of advertisement) without considering the interference of the moderating variable (involvement). As shown in the table, the independent variable (central persuasion) presented a significance $(\mathrm{t}=4.583, \mathrm{P}=0.000<0.05)$. It meant that central persuasion had a significant impact on the effectiveness of advertisement. The interaction item 
between central persuasion and involvement was significant $(\mathrm{t}=3.395, \mathrm{P}=0.001<0.05)$. This indicated that in central persuasion, there was a positive correlation between effectiveness of advertisement and level of involvement. The slope was obviously larger at a high level and smaller at a low level. As shown in figure 6, with the increase of involvement, the effectiveness of advertisement increased.

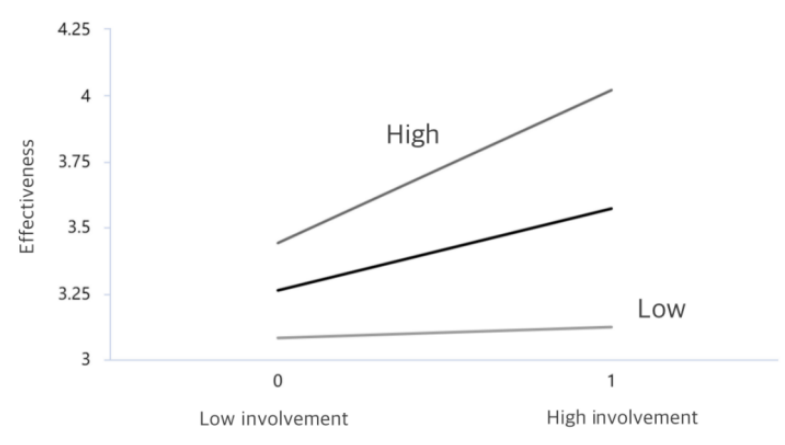

Figure 6 Level of involvement as predictor of effectiveness in central persuasion

Table 5. Regulatory test of peripheral persuasion

\begin{tabular}{cccc}
\multicolumn{3}{c}{ Result } & Model 3 \\
\hline & Model 1 & Model 2 & $3.280^{* *}$ \\
Constant & $3.313^{* *}$ & $3.313^{* *}$ & $(48.872)$ \\
& $(51.770)$ & $(52.096)$ & $0.382^{* *}$ \\
Peripheral persuasion & $0.409^{* *}$ & $0.377^{* *}$ & $(6.448)$ \\
& $(7.199)$ & $(6.338)$ & 0.117 \\
Involvement & & 0.115 & $(1.736)$ \\
Peripheral persuasion & & $(1.694)$ & 0.095 \\
* Involvement & & & $(1.507)$ \\
Sample size & 150 & & 150 \\
$R^{2}$ & 0.259 & 150 & 0.285 \\
Adjusted $R^{2}$ & 0.254 & 0.274 & 0.270 \\
$F$ value & $F(1,148)=51.830, p=0.000$ & $F(2,147)=27.677, p=0.000$ & $F(3,146)=19.368, p=0.000$ \\
$\triangle R^{2}$ & 0.259 & 0.014 & 0.011 \\
$\triangle F$ value & $F(1,148)=51.830, p=0.000$ & $F(1,147)=2.870, p=0.092$ & $F(1,146)=2.270, p=0.134$ \\
\hline
\end{tabular}

Dependent Variable:Effectiveness of advertisement ${ }^{*} p<0.05$ ** $p<0.01$

Similarly, from table 5, we could see that in model 1 , without consideration of involvement, peripheral persuasion had a significant impact on the effectiveness of advertisement. $(\mathrm{t}=7.199, \mathrm{p}=0.000<0.05)$ However, from model 3 , the interaction term between peripheral persuasion and involvement did not show significance $(\mathrm{t}=1.507, \mathrm{P}=0.134>0.05)$. As shown in figure 7 , while peripheral persuasion could influence the effectiveness of advertisement, the impact of high or low involvement was not significant.

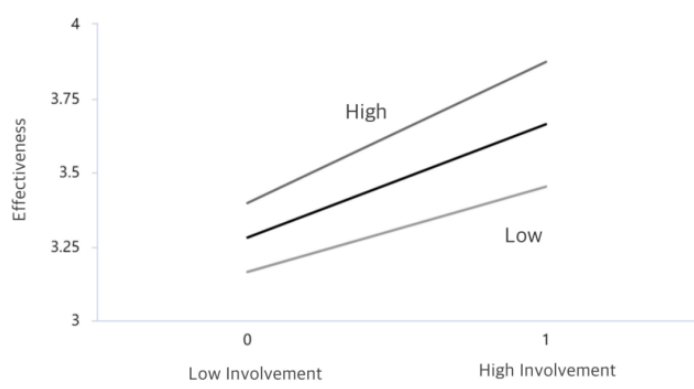

Figure 7 Level of involvement as predictor of effectiveness in peripheral persuasion

\section{CONCLUSION}

Many previous studies suggested that when watching the same content, high involvement would simultaneously induce central thinking, and low involvement would induce peripheral thinking (Petty et al., 1983).[4] The present research separated central persuasion from peripheral persuasion according to the advertisement content and independently manipulated the effect of involvement. The experiment was manipulated successfully, showing that peripheral cues, central cues, and involvement level would impact consumers' desires to purchase the product. The study showed that when people perceive the advertisement argument to be more robust, they would be more willing to purchase the product. In addition, when people were highly involved in persuasion, they would generate more favorable thoughts and form positive opinions about the product. Also, the effect of peripheral persuasion was nearly the same under both high or low involvement, while the effect of central persuasion varied significantly from low to high involvement. This is possible because central persuasion concentrates on people's objective 
evaluation and thoughtful consideration. When people are highly involved in the experiment, they are more likely to judge the details of the arguments and find convincing cues. This corresponds to the result that central route persuasion will show more remarkable temporary persistence on persuasion (Petty \& Cacioppo, 1986).[2] On the contrary, in peripheral persuasion, people do not scrutinize the message, and their emotional appeal is aroused in both low involvement and high involvement conditions.

However, neither central nor peripheral cues can completely account for consumers' attitude change (Petty \& Cacioppo, 1984).[3] There may be other factors influencing the decision-making process. This experiment concluded that peripheral persuasion was more effective in advertising the shoes, but we did not consider other variables. For example, we chose the video format for advertising, and the video lasted about 1 minute. It is confirmed that different media can also affect the efficiency of advertisement (Sama, 2019).[5] In the future, we can study other forms of advertisement such as websites, posters, audio, etc. We can also increase the length of the video to study whether central or peripheral persuasion is more effective when the advertising video is relatively long. Also, in this experiment, we only chose one product (Adidas Boost shoes). In the future, more research can be done to test other objects ranging from different price levels. We can also study whether the number of arguments can affect the persuasiveness of advertisements. These experiments can predict consumers' behaviors and offer more innovative advertisement design techniques to make advertisements more attractive and effective in persuasion.

\section{REFERENCES}

[1] Vakratsas, D., \& Ambler, T. (1999). How Advertising Works: What Do We Really Know? Journal Of Marketing, 63(1), 26.

[2] Petty, R., \& Cacioppo, J. (1986). The Elaboration Likelihood Model of Persuasion. Communication And Persuasion, 1-24.

[3] Petty, R., \& Cacioppo, J. (1984). The effects of involvement on responses to argument quantity and quality: Central and peripheral routes to persuasion. Journal Of Personality And Social Psychology, 46(1), 69-81.

[4] Petty, R., Cacioppo, J., \& Schumann, D. (1983). Central and Peripheral Routes to Advertising Effectiveness: The Moderating Role of Involvement. Journal Of Consumer Research, 10(2), 135.

[5] Sama, R. (2019). Impact of Media Advertisements on Consumer Behaviour. Journal Of Creative Communications, 14(1), 54-68. 